Fourth International Conference on Sustainable Construction Materials and Technologies http://www.claisse.info/Proceedings.htm



SCMT4

Las Vegas, USA, August 7-11, 2016

\title{
Electrochemical Chloride Extraction Treatment of Concrete and the Influences on the Microstructure
}

\author{
Yanxiang Liu' ${ }^{1 a}$, Sen Zeng ${ }^{1 b}$, Changchen Liu'c, and Xinwei Ma ${ }^{1 \mathrm{~d}}$ \\ ${ }^{I}$ Department of Civil Engineering, Harbin Institute of Technology at Weihai, CHINA \\ Corresponding author, ${ }^{\text {ld Email: }<x i n w e i . m a @ 163 . c o m>.}$
}

\begin{abstract}
Reinforced concrete structures in chloride environment are prone to be deteriorated because of chloride ingression. For the existing structures polluted by chloride, chloride could be extracted by electrochemical treatment. Electrochemical chloride extraction (ECE) can suspend the deterioration process, by which the durability could be improved effectively. Experimental research shows that during the chloride extraction, the other ions migrate due to electric potential gradient. Thus the microstructure of concrete changed inevitably. The chloride extracting efficiency at early age is higher, and the discharged chloride is less and less. The chloride discharging rate is related with the voltage. Higher voltage and current density can accelerate the chloride extraction, and the total amount of extracted chloride is more than lower voltage and current. SEM analysis finds the microstructure close to the steel turns looser. The migration of chloride and other substances is confirmed through energy dispersive $\mathrm{x}$-ray analysis (EDAX).
\end{abstract}

\section{INTRODUCTION}

Steel corrosion is one of the most prevalent causes for the deterioration of concrete structure [Metha 1991]. The current statistics shows that chloride ingression is the main reason for the steel corrosion [Godfrey and Chem 2005; Robert and Willis 2003]. For reinforced concrete structures subjected to chlorine ions, electrochemical chloride extraction (ECE) could extract chloride out of the concrete and passivate the corroded steel again without destroying the concrete. It's realized that the steel reinforced concrete structure polluted by chloride could be rehabilitated quickly at a lower cost. In the ECE process, the steel reinforcing cage and an additional metal mesh are applied as cathode and anode, respectively. The free chloride ions in the concrete will have to migrate from cathode to anode when electric field is 
applied. In the process of chloride extraction, other anions and cations in the concrete also migrate in the electric field. Some hydration products may even be decomposed or reformed when the voltage is high enough and lasts a period of time. Previous literature shows that the chloride extraction efficiency can be as high as $80 \%$ or more. While the chloride is discharged, the cohesion between the cement paste and steel could be decreased [Orellan et al. 2004; Siegwart et al. 2003] and the pore structure will also be corresponding changed [Blueneel and Broomfield 1994]. This paper intend to investigate the relationship between chloride extraction efficiency and current density, polarization time, as well as the change of concrete microstructure caused by irons migration.

\section{EXPERIMENTAL INVESTIGATION}

\section{Mixture proportion and specimen}

In this experimental study, PO42.5 Portland cement and S95 pulverized granulated blast furnace slag were used in this study. The cement and slag powder meet the requirements of the related Chinese standards. River sand and crushed limestone were used as a fine and coarse aggregate, respectively. Polycarboxylate superplasticizer was adopted for this study as water reducing admixture. The ribbed carbon steel bar with $12 \mathrm{~mm}$ diameter was used as cathode. $\mathrm{NaCl}$ is admixed in the concrete during the mixing process, the dosage of which is $3 \%$ of the cementitious material. Table 1 presents the mix proportion of the concrete specimen.

Table 1. The mix proportion of the text specimen $\left(\mathrm{kg} / \mathrm{m}^{3}\right)$

\begin{tabular}{|c|c|c|c|c|c|c|c|}
\hline $\begin{array}{c}\text { cement } \\
(\mathrm{PO} 42.5)\end{array}$ & $\begin{array}{c}\text { slag } \\
(\mathrm{S} 95)\end{array}$ & water & $\begin{array}{c}\text { coarse } \\
\text { aggregate }\end{array}$ & $\begin{array}{c}\text { fine } \\
\text { aggregate }\end{array}$ & admixture & $\mathrm{NaCl}$ & total \\
\hline 400 & 60 & 184 & 950 & 750 & 4.6 & 13.8 & 2362.4 \\
\hline
\end{tabular}

Two cylinder specimens, with a diameter of $100 \mathrm{~mm}$ and height of $200 \mathrm{~mm}$ were made in parallel. The steel bar was embedded in the center of the cylinder specimen. After being demolded, the concrete specimens, and steel bars, are packaged with plastic film in order to avoid the loss of chloride and steel corrosion in the process of moist curing.

Experimental. After being cured 28 days, the ECE experiment is conducted. The test apparatus is shown in figure 1. The output range of current is $0 \sim 5 \mathrm{~A}$, and that of voltage is $0 \sim 30 \mathrm{~V}$. The power supply is a stabilized DC power supply with high precision. The current and voltage output are both controlled within $\pm 1 \%$. The anode must be an inert metal that is not easily oxidized. Titanium mesh is used as anode in this experiment; the cathode is steel bar naturally. The saturated $\mathrm{Ca}(\mathrm{OH})_{2}$ solution, which is composed with chemically pure $\mathrm{Ca}(\mathrm{OH})_{2}$ and deionized water, was selected as the electrolyte. In order to keep the alkalinity, and to eliminate the influence of the concentration change, the electrolyte solution was refreshed every 2 days. The concentrations of every replaced solution were measured. To prevent short circuit, the surface of the electrolyte solution should be slightly lower than the top of the specimen all the time. Obviously there should not be a water film on the top surface of specimens. A transparent 
cylindrical aquarium was used as container of the specimen and the electrolyte solution to observe the phenomenon conveniently in the process of experiment. In this experiment, the ECE treatment lasts 12 days, with current density of $1 \mathrm{~A} / \mathrm{m}^{2}$ and $2 \mathrm{~A} / \mathrm{m}^{2}$, respectively.



Figure 1. The test apparatus of ECE

After the ECE test, concrete specimen was broken open longitudinally like figure 2.

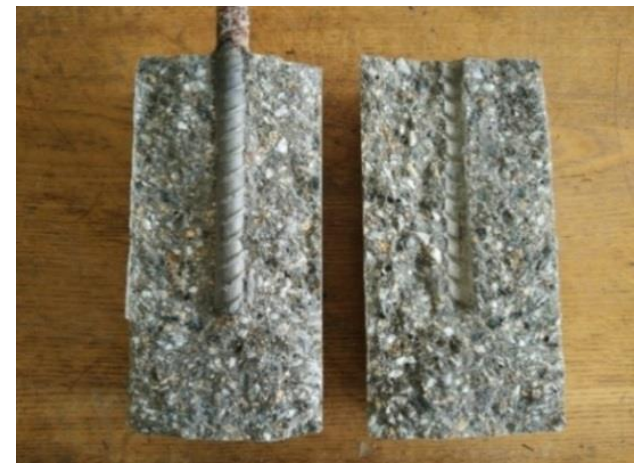

Figure 2. The longitudinal sections after ECE test

Experiments were carried out in steady current conditions. To keep the current in a constant value, the voltage is to be adjusted accordingly. The samples for SEM analysis are taken in positions against steel and closing to the surface respectively. Samples were observed on scanning electron microscope to detect the structure difference between different locations of specimen. The EDAX was also used to observe the microstructure of specimen and the chlorine distribution in concrete before and after test.

\section{RESULTS AND DISCUSSIONS}

Relationship between chloride ion extraction and current density. $\mathrm{Ca}(\mathrm{OH})_{2}$ saturated solution was refreshed every 48 hours, the chloride concentrations of each replaced solution were measured. The chloride concentrations, as well as accumulated extracted chloride are shown in figure 3. Every times the volume of electrolyte solution is 4.2 liters. 


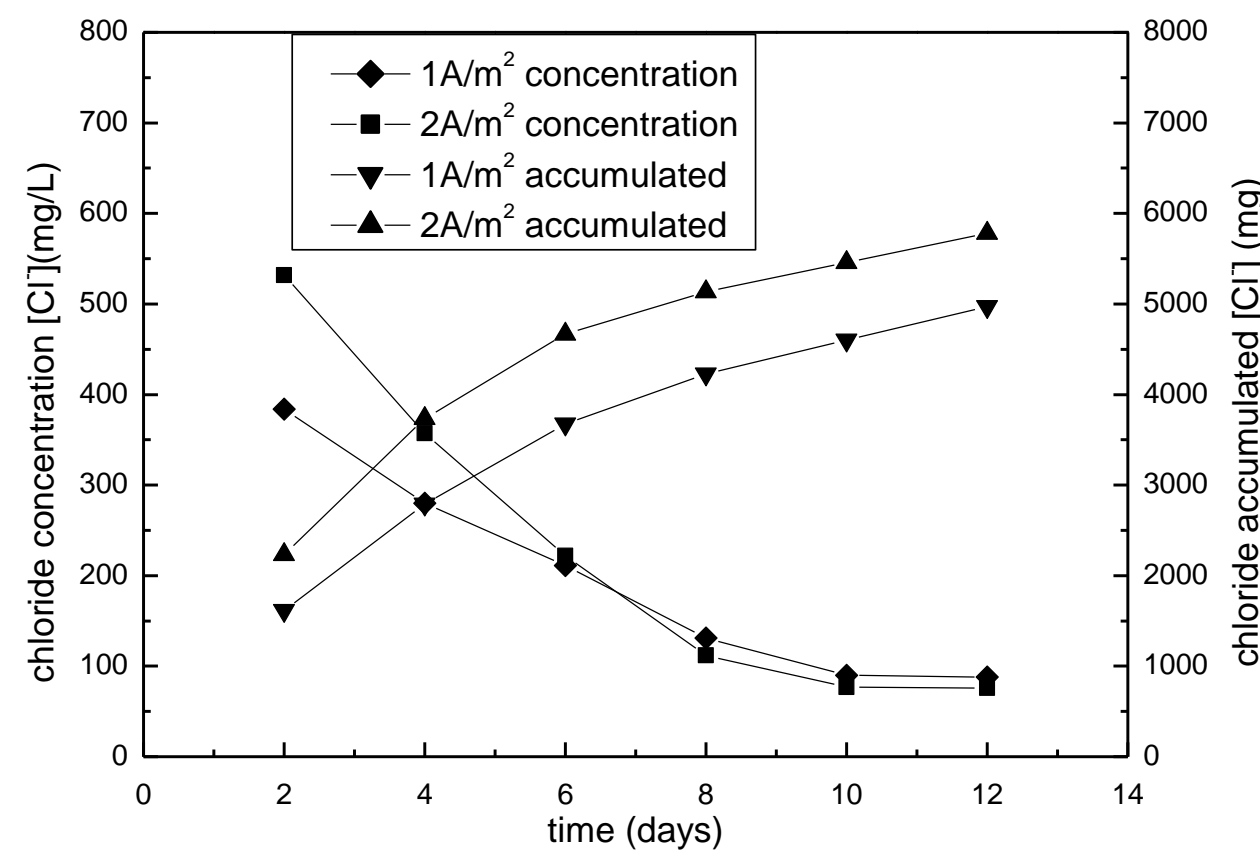

Figure 3. Chloride ion concentration of replaced solution and the accumulated quantity

Figure 3 indicates that the chloride extracting efficiency at early age is higher, and the discharged chloride is less and less. It could be considered that almost all the free chloride is extracted after 8 days ECE treatment. From $7^{\text {th }}$ day and later, less chloride is extracted though the current density and voltage are higher. A higher current density may accelorate the chloride discharging rate, and the total discharged chloride is more than that in lower current density at the same period of time. That means it will take a longer time to extract the free chride in a lower voltage and current. At the end of $12^{\text {th }}$ days, the accumulated extracted chloride ion is up to $5 \mathrm{~g}$ and $6 \mathrm{~g}$ approximately under 2 different voltages, accounts for $38 \%$ and $46 \%$ of the added chloride originally. It seems the percentage of discharged chloride cannot be as high as the results of other researchers. The reason may be that the chloride is added as the concrete is mixed, and some chloride compounded with other substances.

To maintain a stable current density, the appropriate voltage has a tendency to gradually increase. This is because the anion $\left(\mathrm{Cl}^{-}\right.$and $\mathrm{OH}^{-}$etc. $)$and cation $\left(\mathrm{Ca}^{2+}, \mathrm{Na}^{+}\right.$etc. $)$in pore solution lesson gradually. Thus resistance value of specimen increases gradually on the macro. So the voltage output of power supply will rise at the condition of steady current. The decreasing of ions in the pore solution may accelerate decomposition of hydration products and lead to change of the cement paste microstructure [Siegwart 2003].

The change of ion distribution and microstructure. EDAX analysis was carried out on the concrete samples near steel bar and surface of the specimen. Table 3 gives the energy spectrum analysis data, it shows that the quality percentage and atomic number percentage of chlorine near surface of the specimen are $0.75 \%$ and $0.41 \%$ respectively, but chlorine could be not detected around the steel bar. 
Table 3. Data of EDAX near steel bar and surface of the specimen

\begin{tabular}{|c|c|c|c|c|}
\hline \multirow{2}{*}{ Element } & \multicolumn{2}{|c|}{ Around steel bar } & \multicolumn{2}{c|}{ Close to the surface } \\
\cline { 2 - 5 } & $\mathrm{Wt} \%$ & $\mathrm{At} \%$ & $\mathrm{Wt} \%$ & At\% \\
\hline $\mathrm{C}$ & 27.43 & 40.68 & 18.01 & 29.47 \\
\hline $\mathrm{O}$ & 35.74 & 39.78 & 35.88 & 44.07 \\
\hline $\mathrm{Na}$ & 02.23 & 01.73 & 00.94 & 00.81 \\
\hline $\mathrm{Mg}$ & 01.55 & 01.26 & 00.47 & 00.34 \\
\hline $\mathrm{Al}$ & 03.22 & 02.13 & 03.87 & 02.82 \\
\hline $\mathrm{Si}$ & 08.29 & 05.26 & 09.69 & 06.78 \\
\hline $\mathrm{Cl}$ & 00.00 & 00.00 & 00.75 & 00.41 \\
\hline $\mathrm{K}$ & 02.37 & 01.08 & 01.08 & 00.54 \\
\hline $\mathrm{Ca}$ & 20.24 & 08.99 & 28.23 & 13.84 \\
\hline
\end{tabular}

These data show that chloride ions mixed into the concrete actually moved outwards by the action of electric field. So that the content of chlorine near the steel bar is zero or almost close to zero, and the quantity of chlorine near the surface of the specimen is comparatively much higher.

In addition, the quantity of positive ions around the steel is significantly higher than that close to the surface of specimen. This phenomenon is corresponding to the theory that cations will move from anode to cathode when electric field is applied. But there is an exception that the $\mathrm{Ca}$ is opposite to others. One reason is that calcium is prone to be combined in the hydration products, which is hard to migrate. Other reason may be that the $\mathrm{Ca}^{2+}$ in the solution diffuses into the surface of concrete specimen in the ECE process.

After the ECE treatment, the microstructures of concrete around cathode and that close to the surface are analyzed. It is shown in figure 4.

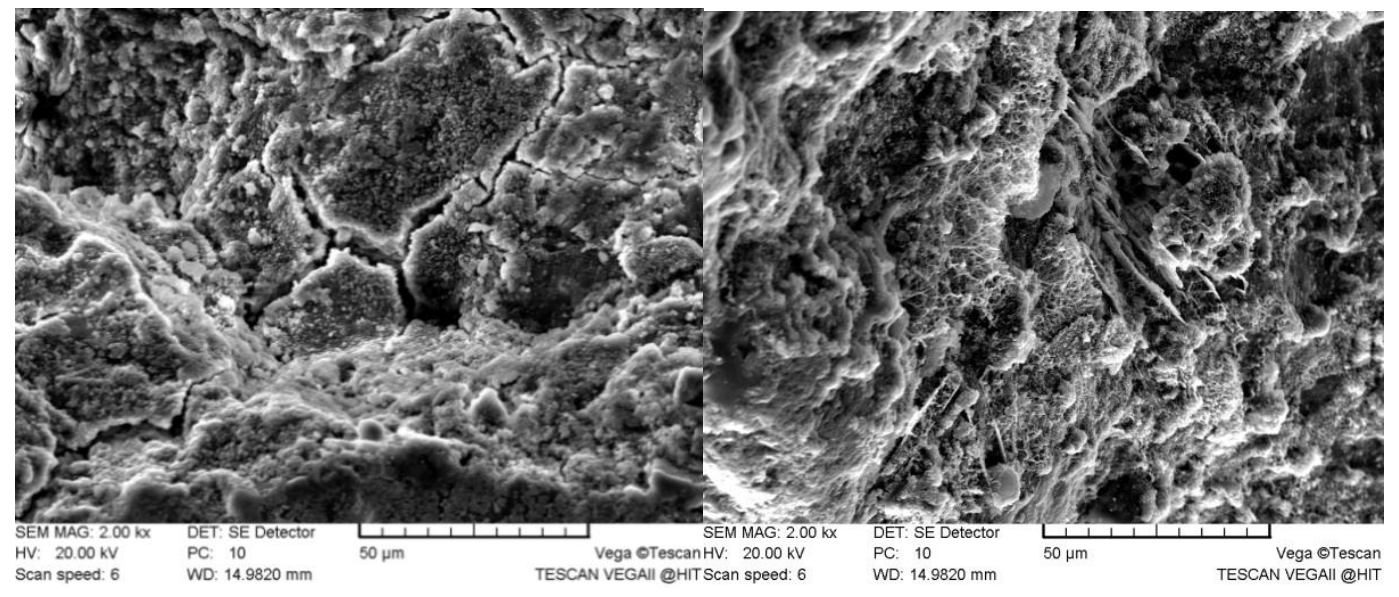

(a) around the steel

(b) close to the surface

Figure 4. The microstructure of around the steel and close the surface 
It can be seen from the picture of cement paste around the bar, the cement paste looser and porous, even some micro cracks appear, while the structure of concrete close to the surface of the specimen is denser. This is due to hydration products like C-S-H and sulphoaluminate of the concrete near the location of cathode decomposed [Siegwart and Lyness and McFarland 2005]. In the shallow surface, the undissolved hydration products composed with calcium ions derived from electrolyte solution and anions extracted from inner concrete filled the pores at the location of near surface of specimen [Wagner and Young and Scheirer 1991].

The increase of porosity around the steel bar due to the decomposition of hydration products will weaken the bond between concrete and steel. To some extent, the decrease of bond force will cause an adverse effect to the reinforced concrete structure. Although academia has a lot of research for this problem, no reasonable approach is recommended to eliminate or reduce the adverse effect on the bond between steel bar and concrete in ECE.

Up to now, this technology has not been wildly used in real projects. Under the condition of that the reinforced concrete member and the positive pole (titanium mesh) are insulated from the earth and other adjacent, it works undoubtedly. For the large concrete members, a large power supply is required correspondingly. The accumulation of alkali around the bar may probably stimulate alkali-silica reaction, but it has not been detected. The influence of the local structure changes on the bond strength of reinforcing steel is to be further studied.

\section{CONCLUSION}

Based on a series of experiments, the effect of ECE treatment is confirmed. The relationships between ECE effect, current density and the polarization time were investigated. The change of ion distribution and microstructure of concrete was also discussed. The following conclusions can be draw from the previous research.

- The chlorine ion could be extracted efficiently at the begainning, but the extracting rate decreases gradually. It could be considered that almost all the free chloride is extracted after 6 days ECE treatment. A higher current density can improve the efficiency of chlorine ion extraction, as well as the accumulated amount of chloride.

- With the decrease of the free ions in pore solution, the resistance value of specimen gradually increases. Therefore the output voltage of power supply will rise under the condition of steady current.

- During the process of ECE, cations like $\mathrm{K}^{+}$and $\mathrm{Na}^{+}$were concentrated in the location near the bar, and anions migrate to the concrete surface. The migration of ion could change the structure of cement paste. The pore structure of concrete near cathode turns coarsening, but the shallow surface of the concrete turns more compacted because of combination of anions from the inner pore solution and calcium ions from the exterior electrolyte solution. 


\section{ACKNOWLEDGEMENTS}

Support for this research project came from Science and Technology Development Projects of Weihai (NO. 2014DXGJ09).

\section{REFERENCES}

Blueneel, D. N. R., and Broomfield, J. P. (1994). "Effect of Chloride Removal on Rebar Bond Strength and Concrete Propertie." Proceedings of International Conference on Corrosion and Corrosion Protection of Steel in Concrete, 1994, 1438- 1450.

Godfrey, M. R., and Chem, T. Y. (2005). "Some Principles of Service Life Calculation of Reinforcements and in Situ Corrosion Monitoring by Sensors in the Radioactive Waste Containers." Corrosion, 2005, 51(10):797-804.

Mehta, P. K. (1991). "Durability of Concrete-Fifty Years of Progress." Durability of Concrete - G.M.I dorn International Symposium, Detroit, 1991. American Concrete International SP-126.

Orellan, J.C., and Escadeillas, G., and Arliguie, G. (2004). "Electrochemical Chloride Extraction: Efficiency and Side Effects." Cement and Concrete Research., 2004, 34 (2) : 227.

Robert, S., and Willis, J. (2003). "Electrochemical Methods in Corrosion on Petroleum Industry Laboratory and Field Results.” R.U .S., 2003, 2 (5):306-414.

Siegwart, M., and Lyness, J. F., and McFarland, B. J. (2003). "Change of Pore Size in Concrete Due to Electrochemical Chloride Extraction and Possible Implications for the Migration of Ions." Cement and Concrete Research., 2003, 33(8)1211-1221.

Siegwart, M., and Lyness, J. F., and McFarland, B. J. (2005). "The Effect of Electrochemical Chloride Extraction on Pre-stressed Concrete." Construction and Building Materials., 2005, 19(8): 585 594.

Wagner, J., and Young, W., and Scheirer, S. (1991). "Cathodic Protection of Prestressed Members: an Update.” Transport Research Record., 1991, (1304):144-152. 